\title{
The Carioca High and Low Conditioned Freezing Lines: A New Animal Model of Generalized Anxiety Disorder
}

\author{
Vitor de Castro Gomes ${ }^{1}$, Carlos Eduardo Barroso Silva ${ }^{1}$ \\ and J. Landeira-Fernandez ${ }^{1,2}$ \\ ${ }^{1}$ Pontifícia Universidade Católica do Rio de Janeiro, Rio de Janeiro, RJ, \\ 2Universidade Estácio de Sá, Rio de Janeiro, RJ, \\ Brazil
}

\section{Introduction}

Fear and anxiety are complex concepts. Both terms have been used to describe a set of highly orchestrated neural events that involve sensory processing and motor responses triggered by threatening situations. These events are mediated by central neural circuitries and peripheral neuroendocrine pathways and clearly have adaptive value. Sensory systems function as alerting signals to warn of real or potential danger, producing a shift to a state of high vigilance that prepares the individual to avoid or escape from a wide variety of dangerous situations. Most of these reactions are not exclusive to our species. Because of their importance for survival, fear and anxiety traits are believed to have been selected in human evolution and shaped by natural selection for their crucial role in protecting individuals who face adverse environments (Coutinho et al., 2010; Gross \& Hen, 2004; Marks \& Nesse, 1994).

However, these highly adaptive events can be disabling when the individual experiences them excessively or when they occur in the absence of threatening stimuli. In these cases, they represent a pathological condition termed an anxiety disorder. Often chronic in nature, these disorders are among the most prevalent mental health problems across the individual life span, producing severe impairments in social and occupational functioning.

According to an evolutionary perspective, an anxiety disorder reflects a malfunctioning of the neural circuits responsible for detecting, organizing, or expressing adaptive defense reactions (Jacobson \& Cryan, 2010). Humans and nonhuman mammals share approximately the same behavioral defense strategies, reflected by activation of similar underlying neural circuitry. Therefore, animal models of anxiety can be extremely helpful for better understanding the behavioral, neural, and genetic substrates involved in these pathologies. The purpose of the present chapter is to present two new lines of rats that might be a useful model of generalized anxiety disorder (GAD). Before we discuss this model, defining how anxiety disorders are currently classified is important.

\section{Clinical aspects of anxiety}

The concept of anxiety disorders has changed dramatically over the years as more clinical and experimental evidence has been collected. In the clinical setting, anxiety disorders 
departed from a single construct that ranged in intensity from normal to pathological or neurotic levels. A major shift in this view occurred with Klein's pioneering work (Klein, 1964; Klein \& Fink, 1962), which showed that imipramine had a selective effect in the treatment of panic disorder. Moreover, certain anxiety disorders have been suggested to differ from each other in the primary object or specificity of threat. Fear of a circumscribed and well-defined object is a characteristic of specific phobias, whereas diffuse and chronic sustained anxiety is the main feature of GAD.

The $3^{\text {rd }}$ edition of the Diagnostic and Statistical Manual of Mental Disorders (DSM-III; American Psychiatric Association, 1980) introduced the current descriptive symptom-based approach to mental disorders with well-defined, explicit diagnostic criteria. This new classification incorporated distinct nosological entities, such as panic disorder, specific and social phobias, GAD, posttraumatic stress disorder, and obsessive-compulsive disorder. In the DSM-III, GAD was left as a residual diagnosis of worry, to be made only in the absence of other anxiety and depressive syndromes. Consequently, this residual category carried low diagnostic reliability.

With the publication of the DSM-IV (American Psychiatric Association, 1994) and International Classification of Diseases and Related Health Problems (ICD-10; World Health Organization, 1992), these anxiety disorder categories remained basically the same. However, the diagnosis of GAD shifted from a residual category in the DSM-III to an independent anxiety disorder type in the DSM-IV. Free-floating anxiety was associated with the worry construct, which in turn produced several symptoms, such as muscle tension, fatigue, restlessness, concentration difficulties, and irritability. According to the DSM-IV, excessive and unrelenting worry is generally associated with impairments in academic, social, and personal functioning and related to multiple domains or activities. To be considered a pathological feature of GAD, worry must occur more days than not for a period of at least 6 months.

\section{Animal models of anxiety}

In the experimental setting, most of the studies that investigate the etiological mechanisms that underlie anxiety disorders have been performed using animal models. Defensive reactions of the laboratory rat (Rattus norvegicus) have been employed as the main system for modeling human anxiety. Defecation in the open field was probably one of the first animal models of anxiety (Hall, 1934). Since then, several other animal models of anxiety have been developed. As in the clinical setting, the traditional view that highlighted these experimental studies was that animal defensive responses were mediated by a single and general anxiety construct (Broadhurst, 1975; Gray, 1979; Hall, 1934). Nevertheless, as new data were collected, it became clear that animal defensive behavior is mediated by a complex and multidimensional construct (Aguilar et al., 2002; Belzung \& Le Pape, 1994; Ramos et al., 1997; Torrejais et al., 2008). In these studies, statistical techniques, such as factor analysis, were employed to investigate whether different animal models of anxiety measure the same underlying latent factor. The results clearly indicated that different animal models assessed distinct forms of anxiety. For example, File (1992) showed that indices of anxiety derived from the elevated plus maze (i.e., the number of entries into and time spent on the open arms of the maze), Vogel conflict test (i.e., frequency of punished drinking), and social interaction test (i.e., time spent engaged in social interaction), loaded on three independent factors, suggesting the existence of different forms of anxiety generated by each of these paradigms. 
Pharmacological studies that employed diverse animal models also confirmed the multidimensional aspect of anxiety. For example, benzodiazepine compounds produced an anxiolytic effect in animal models that generate behavioral inhibition caused by the conflict between approach and avoidance tendencies (Maki et al., 2000). These animal models also indicated that substances that decrease serotonergic neurotransmission increase anxiety, whereas compounds that increase serotonergic neurotransmission decrease anxiety (Graeff, 1997). In contrast, other animal models that require vigorous escape responses to proximal aversive stimuli appear to be resistant to benzodiazepine drugs, whereas substances that increase serotonergic activity produce an anxiolytic effect (Graeff and Zangrossi, 2010).

Different neural circuitries appear to be involved in distinct dimensions of anxiety. Gray and McNaughton (2000) argued that the septo-hippocampal system contributes to the cognitive component (worry), and the amygdaloid complex and its projections to the ventral portion of the periaqueductal gray (PAG) are critically involved in the regulation of inhibitory behavior in response to innate or conditioned aversive stimuli (Fanselow, 1994). Active defensive behaviors in response to proximal stimuli, generally associated with nociception, appear to involve the dorsal portion of the PAG (dPAG) and its ascending projections to forebrain structures related to the sensorial processing of aversive stimuli (Oliveira et al., 2004).

These diverse dimensions found in animal models of anxiety may indicate that clinically defined anxiety disorders could be associated with a particular animal model. However, the adoption of descriptive and operational criteria from the modern classification systems imposed a validity problem among the several anxiety disorder categories. The DSM-IV and ICD-10 are not primarily based upon etiology, neurobiology, epidemiology, genetics, or responses to medications, but rather on phenomenological descriptions of clinical data that have imprecise similarity or correlate with each other within and between individuals (Gould \& Gottesman, 2006). Therefore, unsurprising are the several problems that are encountered when attempting to use the current systems of mental disorder classification as a guide for developing viable animal models.

\section{Contextual fear conditioning as a model of generalized anxiety disorder}

Regardless of the difficulty developing animal models for current clinically defined anxiety disorders, fear conditioning has been historically associated with one of the main causes of pathological anxiety (i.e., neurosis; Pavlov, 1927; Watson \& Rayner, 1920). In a typical fear conditioning experiment, a discrete and emotionally neutral stimulus, such as a light or tone, reliably signals the occurrence of an aversive stimulus, such as an electric footshock. After a few pairings between these two stimuli, the previously harmless stimulus becomes a potent conditioned stimulus (CS) and acquires the ability to elicit several fear reactions.

Another form of fear conditioning is to make the aversive stimulus unpredictable. According to this alternative procedure, a rat is exposed to a novel chamber and, after a few minutes, a brief and unsignaled footshock is delivered. When returned to the same chamber in the absence of the aversive stimulus, the animal presents a permanent fear reaction to contextual cues previously associated with the footshock.

Considerable evidence from animal and human experiments indicate that fear conditioning in response to a discrete CS and contextual cues is mediated by different neural circuitries (Indovina et al., 2011; Ferreira et al., 2003; Kim \& Fanselow, 1992; LeDoux, 2000; Pohlack et al., 2011). These results support the hypothesis of at least two dimensions of fear conditioning, and 
each dimension might be related to clinically distinct anxiety disorders. Specific phobias, characterized by cue-specific or phasic fear reactivity, might be modeled by aversive conditioning in response to a discrete CS (Grillon, 2002; Grillon and Davis, 1997). GAD, in contrast, is characterized by persistent and diffuse or non-cue-specific anxiety and might be modeled by contextual fear conditioning (Brandão et al., 2008; Grillon and Davis, 1997).

Contextual fear conditioning represents one of the simplest and most rapid forms of producing aversive learning (Landeira-Fernandez, 1996). Defensive freezing behavior has been argued to be the most reliable measure of contextual fear conditioning (Fanselow, 1984a). This defensive response is a direct function of shock intensity (Sigmundi et al., 1980) and depends on the association between the cues of the experimental chamber and footshock (Landeira-Fernandez et al., 2006).

Conditioned freezing in response to contextual cues previously associated with footshock has been pharmacologically validated as an adequate model of anxiety disorder. Accordingly, classic anxiolytic benzodiazepines, such as midazolam and diazepam (Fanselow and Helmstetter, 1988), and non-benzodiazepine anxiolytics, such as the serotonin-1A (5-hydroxytryptamine-1A [5- $\left.\mathrm{HT}_{1 \mathrm{~A}}\right]$ ) receptor agonist ipsapirone (Inoue, Tsuchiya, Koyama, 1996) and 5-HT reuptake inhibitors citalopram and fluvoxamine (Hashimoto et al., 1996), reduced the amount of conditioned freezing. Furthermore, anxiogenic substances, such the benzodiazepine inverse agonist dimethoxy- $\beta$-carboline, produced freezing behavior similar to that elicited by fear conditioning (Fanselow et al., 1991).

\section{The Carioca High and Low conditioned Freezing rats}

Bidirectional selective breeding of a defensive response or any other phenotypic characteristic is a technique in which animals are bred to modify the frequency of the genes that underlie a particular phenotype. Mating animals within a population based on the opposite extremes of an observable characteristic will push, over many generations, this particular phenotype in opposite directions, leading to two separately bred lines. This technique has been widely employed to investigate how genes can influence various behavioral traits, including defensive reactions associated with emotionality. In particular, genetic animal models of anxiety disorders might be a useful tool for understanding why some individuals present adequate emotional reactions and others endure an exaggerated pattern of anxiety responses in the absence of a fear-provoking context.

The view that anxiety does not reflect a single or unitary process emphasizes the importance of developing different genetic models with distinct phenotype criteria. In fact, the development of bidirectional lines of animals with high and low levels of emotionality began in the middle of the $20^{\text {th }}$ century. Since then, a relatively large number of different lines have been described in the literature (for review, see Ramos and Mormède, 2006). Innate and learned animal models have been employed for mating selection in rats. Among the innate models are defecation (Maudsley animals; Broadhurst, 1957, 1958) and ambulation in the center of an open field apparatus (Floripa animals; Ramos et al., 2003), ambulation on a runway (Tsukuba animals; Fujita, 1984), open arm parameters in the elevated plus maze (HAB and LAB animals; Liebsch et al., 1998a, b), and infant isolationinduced ultrasonic vocalizations (USV animals; Brunelli \& Hofer, 1996). Surprisingly, the two-way-avoidance response has been the main conditioned phenotype criterion used for developing bidirectionally selected rat lines based on learned aversive paradigms. That is 
the case for Roman (Bignami, 1965), Syracuse (Brush et al., 1979), Australian (Bammer, 1983), Koltushi (Ryzhova et al., 1983), and Hatano (Ohta et al., 1995) animals.

Our group in the Psychology Department at Pontifícia Universidade Católica do Rio de Janeiro (PUC-Rio) was also interested in developing a rat genetic model of extreme phenotypes of learned fear. Instead of the two-way avoidance paradigm, conditioned freezing in response to contextual cues previously associated with footshock was employed as the phenotype criterion for developing the two lines. The breeding program began in 2006. The basic protocol consisted of mating male and female albino Wistar rats with the highest and lowest conditioned freezing in response to the contextual cues of the experimental chamber where animals were exposed to three unsignaled electric footshocks on the previous day. Gomes and Landeira-Fernandez (2008) found that after three generations, reliable differences between these two lines were already present, indicating a strong heritable component of this type of learning. The lines were named Carioca ${ }^{1}$ High conditioned Freezing (CHF) and Carioca Low conditioned Freezing (CLF). These two lines represent the most recent rat genetic model in the field of anxiety.

\section{Phenotype results of the $12^{\text {th }}$ generation}

To illustrate the development of our breeding lines, we present the phenotype results of the $12^{\text {th }}$ generation of the CHF and CLF lines recently collected in our laboratory. A random (RND) line of randomly selected rats was also used as a control group for the CHF and CLF lines. Phenotyping was performed on a total of 122 animals from the CHF line (67 males and 55 females), 124 animals from the RND line (54 males and 70 females), and 99 animals from the CLF line (49 males and 50 females).

Animals were born and maintained in the colony room of the PUC-Rio Psychology Department with controlled room temperature $\left(24 \pm 1^{\circ} \mathrm{C}\right)$ and a $12 \mathrm{~h} / 12 \mathrm{~h}$ light/dark cycle (07:00-19:00 h). To assign a control number for each animal, amputation of one toe from each foot and a small incision in one of the ears was performed 6 to 8 days after birth. Upon weaning at 21 days of age, each animal was separated by sex and housed in groups of five to seven, according to their respective lines, in polycarbonate cages $(18 \times 31 \times 38 \mathrm{~cm})$ with food and water available ad libitum. Phenotyping occurred during the light phase of the cycle. The animals were between 75 and 80 days of age at the beginning of the experiment. For 5 days before the contextual fear conditioning experiment, the animals were handled once daily for a period of $2 \mathrm{~min}$.

Contextual fear conditioning occurred in four observation chambers $(25 \times 20 \times 20 \mathrm{~cm})$, each placed inside a sound-attenuating box. A red light bulb $(25 \mathrm{~W})$ was placed inside the box, and a video camera was mounted in the back of the observation chamber so the animal's behavior could be observed on a monitor outside the experimental chamber. A ventilation fan attached to the box supplied background noise of $78 \mathrm{~dB}$ (A scale). The floor of the observation chamber consisted of 15 stainless steel rods (4 mm diameter) spaced $1.5 \mathrm{~cm}$ apart (center-to-center), which were wired to a shock generator and scrambler (Insight, São Paulo, Brazil). An interface with eight channels (Insight) connected the shock generator to a computer, which allowed the experimenter to apply an electric footshock. Ammonium hydroxide solution (5\%) was used to clean the chamber before and after each subject.

${ }^{1}$ Carioca is the name given to those born in Rio de Janeiro. 
The contextual fear conditioning protocol involved one acquisition session and one test session. During acquisition, each animal was placed in the observation chamber for $8 \mathrm{~min}$. At the end of this period, three unsignaled $0.6 \mathrm{~mA}, 1 \mathrm{~s}$ electric footshocks were delivered with an intershock interval of $20 \mathrm{~s}$. Three minutes after the last footshock (post-shock interval), the animal was returned to its home cage. The test session occurred approximately $24 \mathrm{~h}$ after training. This test consisted of placing the animal for $8 \mathrm{~min}$ in the same chamber in which the three footshocks were delivered on the previous day. No footshock or other stimulation occurred during this period. A time-sampling procedure was used to evaluate fear conditioning in response to contextual cues. Every $2 \mathrm{~s}$, the animal was observed, and a welltrained observer recorded episodes of freezing, defined as the total absence of movement of the body or vibrissa, with the exception of movements required for respiration.

Previous results from our laboratory indicated that male rats consistently exhibited more conditioned freezing in response to contextual cues than female animals (Gomes and Landeira-Fernandez, 2008). Therefore, male and female results are presented separately. Fig. 1 presents the mean \pm standard error of the mean (SEM) percentage of time spent freezing among male and female rats of the CHF, RND, and CLF lines during the post-shock period. The results were analyzed using a two-way analysis of variance (ANOVA). The first factor, with two levels, was related to the animal's sex (male and female). The second factor, with three levels, was related to the breeding line (CHF, RDN, and CLF).

This analysis revealed an absence of a two-way interaction $\left(F_{2,339}=0.44, p>0.6\right)$. A main effect of sex was found $\left(F_{1,339}=14.02, p<0.001\right)$. As shown in Fig. 1 , male rats expressed more freezing behavior than female rats across all three levels of the breeding line factors. A main effect of breeding line was also detected $\left(F_{2,339}=20.27, p<0.001\right)$. Pairwise post hoc comparisons performed with Fisher's Least Significant Difference test indicated that CLF animals expressed lower freezing behavior compared with CHF and RND animals (all $p<$ 0.001). Finally, CHF and RND animals did not differ significantly from each other $(p>0.4)$.

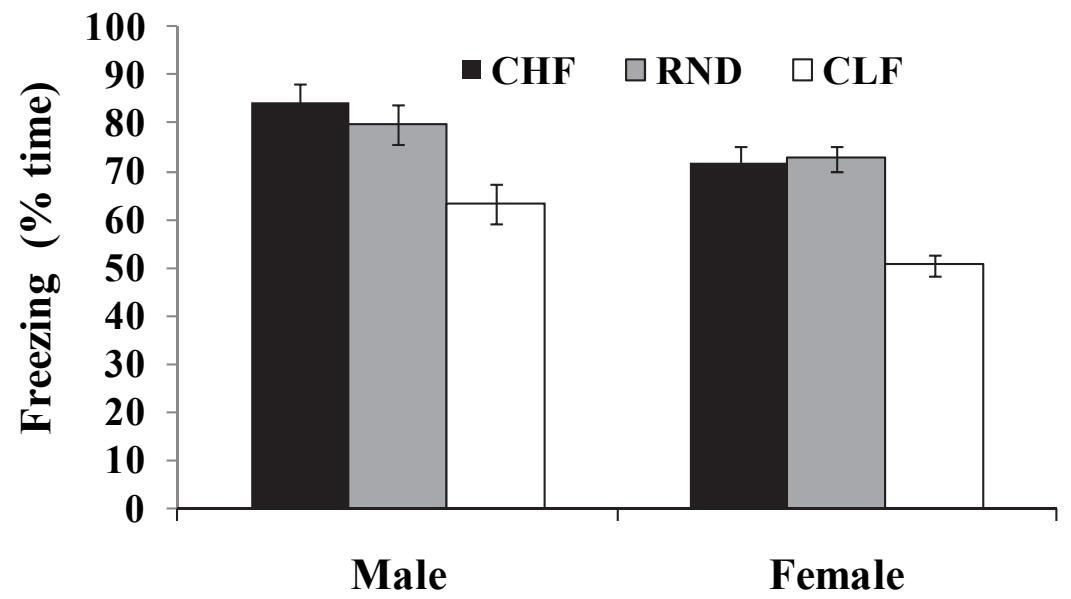

Fig. 1. Mean \pm SEM percentage of time spent freezing among male and female rats of the high (CHF), random (RND), and low (CLF) lines during the post-shock period of the training session. 
The differences observed in the amount of post-shock freezing behavior between CLF and $\mathrm{CHL}$ animals were not observed in our original report that employed the 3 rd generation of these two lines (Gomes and Landeira-Fernandez, 2008). Three possibilities may explain these discrepant results. One is that the footshock intensity used to phenotype animals of the present generation $(0.6 \mathrm{~mA})$ was much lower than the intensity used during the first three generations (1.0 mA) reported by Gomes and Landeira-Fenandez (2008). Therefore, the higher footshock intensity could lead to a ceiling effect so that differences in post-shock freezing behavior may not be observed. Indeed, the footshock intensity was reduced in our breeding program in the $7^{\text {th }}$ generation to $0.7 \mathrm{~mA}$ and in the $8^{\text {th }}$ generation to the present intensity to prevent possible ceiling effects produced by this relatively strong $(1.0 \mathrm{~mA})$ footshock intensity.

A second possibility could be related to the fact that freezing observed immediately after footshock reflects associative learning between contextual cues and the aversive footshock (Fanselow, 1980, 1990; Vianna et al., 2001b). For example, when the footshock is presented simultaneously with the rat's placement in the chamber, no contextual fear conditioning is observed (Landeira-Fernandez et al., 1995). Moreover, placing the animal in a different context from the one in which the footshock was delivered did not produce any freezing behavior (Fanselow, 1980). Therefore, differences between CHF and CLF animals in postshock freezing could be a consequence of the fact that $\mathrm{CHF}$ rats have a greater propensity for exhibiting higher conditioned freezing responses compared with CLF animals because of the continuous bidirectional selection over different generations.

A third possible explanation for these incongruent results might be related to differences in pain sensitivity between these two lines. This is an important issue because freezing observed immediately after footshock is closely related to pain sensitivity and shock intensity (Fanselow, 1984b). According to this possibility, selection for high and low conditioned freezing might independently lead to co-selection of other contributing factors that are not genetically linked but contribute to the phenotype that is being selected, such as differences in pain sensitivity to footshock. Further studies are necessary to test this possibility.

Fig. 2 presents the mean and SEM percentage of time spent freezing among male and female rats of the high (CHF), random (RND), and low (CLF) lines during the 8 min test session. Conditioned freezing in response to contextual cues previously associated with footshock was also analyzed using a two-way ANOVA. This analysis indicated an absence of a twoway interaction $\left(F_{2,339}=0.07, p>0.9\right)$. A main effect of sex was found $\left(F_{1,339}=41.85, p<\right.$ 0.001). As shown in Fig. 2, male rats froze more than female rats across all three levels of the breeding line factors. A main effect of breeding line was also detected $\left(F_{2,339}=18.13, p<\right.$ 0.001). Fig. 2 also shows that the CHF line expressed the highest amount of conditioned freezing, and the CLF line expressed the lowest amount of freezing. The RND line presented intermediate levels of freezing. These results were confirmed by pairwise post hoc comparisons. CHL animals froze more than RND and CLF animals, and CLF rats froze less than CHF and RDN animals (all $p<0.01$ ).

Electric footshock induced a reliable difference between CHF and CLF animals, and we evaluated whether the breeding line effect on conditioned freezing during the test session was attributable to post-shock differences that these animals presented during the training session. An analysis of covariance, with post-shock as a covariant factor, was performed. The results from this analysis confirmed an absence of an interaction $\left(F_{2,338}=0.19, p>0.8\right)$ and main effects of $\operatorname{sex}\left(F_{1,338}=31.14, p<0.001\right)$ and breeding line $\left(F_{2,338}=10.23, p<0.001\right)$. 
These results confirmed previous findings from our original report (Gomes and LandeiraFernandez, 2008) and extend these results to a control group of animals that were randomly mated.

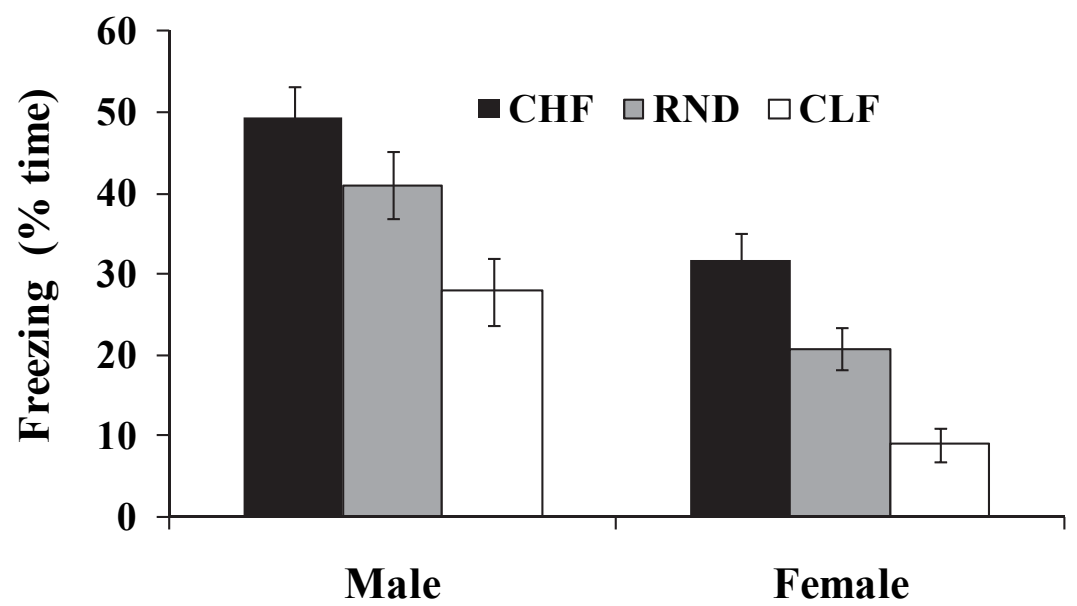

Fig. 2. Mean \pm SEM percentage of time spent freezing among male and female rats of the high (CHF), random (RND), and low (CLF) lines during the test session $24 \mathrm{~h}$ after training.

\section{Behavioral validation of the Carioca lines}

An important issue in the processes of developing a new genetic animal model of anxiety is to evaluate whether the pair of contrasting lines of rats selectively bred for high and low anxiety-related responses also display convergent results in other threatening situations that also require the activation of defensive responses. The first behavioral results from this ongoing selective breeding program were reported by Dias et al. (2009). They performed a battery of behavioral tests that evaluated the emotional and cognitive aspects of the $4^{\text {th }}$ generation of the CHF and RND lines. To evaluate anxiety-related behaviors, the CHF and RND lines were tested in the elevated plus maze and social interaction test. CHF animals were significantly more emotionally reactive than RDN rats in terms of both the number of entries into and time spent on the open arms of the elevated plus maze. The time spent engaged in social interaction behavior was also significantly decreased. Importantly, no differences were found in locomotor activity, measured by the number of entries into the closed arms of the elevated plus maze and number of crossings in the social interaction test arena. Therefore, motor activity did not account for the differences between CHF and RDN animals.

Dias et al. (2009) also found an absence of differences between the CHF and RND lines in the forced swim test, suggesting that the anxiety trait selected in the CHF line did not interact with affective disorder traits, such as those for depression. The cognitive aspects of $\mathrm{CHF}$ rats were evaluated in the object recognition task. The results from this test indicated no difference between the two groups. These negative results indicated that our breeding procedure, which increased the occurrence of conditioned freezing in response to contextual 
cues previously associated with footshock, did not interfere with other emotional or memory systems. Although these results are extremely encouraging, additional experiments are necessary to further evaluate the behavioral profile of each of these lines.

\section{Panic-related behaviours in the Carioca lines}

Panic disorder is a complex anxiety disorder that involves both recurrent, unexpected panic attacks and persistent concern about having additional attacks (American Psychiatric Association, 1994). Although the occurrence of a panic attack is a hallmark of panic disorder, the chronic conditioning of this anxiety disorder is defined by the constant and persistent fear of experiencing further attacks or worry about the possible consequences of a panic attack.

The clinical concept of panic attack and panic disorder is well described in the literature (Freire et al., 2010). However, the relationship between an anticipatory anxiety trait present in GAD with panic attack and the development of panic disorder remains a subject of intense debate (Battaglia and Ogliari, 2005; Bouton et al., 2001; Stein et al., 2010). The distinction between panic disorder and GAD stemmed from Klein's original observations (Klein, 1964; Klein and Fink, 1962), in which chronic administration of the antidepressant imipramine improved panic disorder, which was resistant to benzodiazepine anxiolytics at doses that improved GAD. This pharmacological distinction between these two anxiety disorder categories has been further qualified. Chronic imipramine also improves GAD (Kahn et al. 1986), and high-potency benzodiazepines, such as alprazolam, are effective in panic disorder when chronically administered (Schweizer et al. 1993).

Empirical research has successfully employed electrical stimulation of the dPAG as a useful animal model of both panic attack (i.e., the acute reaction that might trigger the panic disorder condition) and panic disorder (i.e., the chronic or continuous condition that characterizes the full expression of this anxiety disorder). A stepwise increase in the electrical current intensity used to stimulate the dPAG in rats produces a suppression of spontaneous locomotor activity (i.e., freezing) accompanied by piloerection and exophthalmus at lower intensities. As stimulation continues, active escape behaviors, such as running and jumping, appear at higher intensities (Brandão et at., 1982). After the termination of the dPAG electrical stimulation at the escape threshold, the animal engages in a long-lasting freezing response (Vianna et al., 2001a). Freezing and escape responses triggered by electrical stimulation of the dPAG represent a model of panic attack, whereas dPAG post-stimulation freezing at the aversive escape threshold appears to be a model of panic disorder (for review, see Brandão et al., 2008).

Recently, Galvão et al. (in press) exposed CHF and CLF animals from the 9th generation to the dPAG electrical stimulation paradigm. The results indicated that CHF animals had a higher dPAG electrical stimulation aversive threshold for producing freezing and escape reactions than CLF animals. However, CHF animals displayed more freezing behavior immediately after dPAG electrical stimulation at the escape threshold compared with CLF animals. Thus, although CHF animals were more resistant to the expression of freezing and escape behavior in response to dPAG stimulation, they were more prone to freezing after the occurrence of the dPAG aversive stimulation compared with CLF animals. These results are consistent with the interpretation that although anticipatory anxiety might exert an inhibitory effect on the expression of panic attack, it might also facilitate the pathogenesis of panic disorder. 


\section{Conclusions}

Anxiety disorders are among the most prevalent mental health problems across the individual life span. Early clinical and experimental conceptualizations of anxiety departed from a single or unitary general trait model. More recent theories have favored the view that anxiety is a complex, multidimensional, and dynamic phenomenon. Animal modeling has been crucial in dissecting the pathophysiological mechanisms and designing more effective therapies. Contextual fear conditioning has clear isomorphism with GAD, whereas electrical stimulation of the dPAG appears to be a valid animal model of panic attack and panic disorders.

Bidirectional selection for high and low anxiety-like behavior is a valuable tool for understanding the neural substrates of anxiety disorders. Our laboratory recently developed two new lines of Wistar rats, CHF and CLF, that were selectively bred for high and low levels of freezing in response to contextual cues previously associated with footshock. After three generations of breeding, CHF rats were considered to have a greater propensity for exhibiting higher conditioned freezing responses compared with CLF animals. The present phenotype results of our $12^{\text {th }}$ generation indicated that CHF and CLF lines differed from each other and from a RND control line. CHF and CLF animals also presented a difference in freezing triggered immediately after the occurrence of footshock.

The results from the $4^{\text {th }}$ generation also indicated that CHF animals were more "anxious" than RND rats in the elevated plus maze and social interaction test. Motor activity did not account for the differences between the CHF and RND lines. The absence of reliable differences between CHF and RND animals in the forced swim test and object recognition task indicated that the breeding procedure, which increased the occurrence of conditioned freezing in response to contextual cues, did not interfere with other emotional or memory systems. Finally, exposure of CHL and CLF animals to electrical stimulation of the dPAG suggested that the component of anticipatory anxiety present in GAD might exert an inhibitory effect on the expression of panic attack, whereas it might also facilitate the pathogenesis of panic disorder.

\section{Acknowledgments}

JLF was supported by a grant from the Brazilian National Research Council (CNPq, 522720/95-10). VCG and CEBS were supported by graduate student fellowships from CNPq and PUC-Rio, respectively.

\section{References}

Aguilar, R., Gil, L., Flint, J., Gray, J.A., Dawson, G.R., Driscoll, P., Giménez-Llort, L., Escorihuela, R.M., Fernández-Teruel, A. \& Tobeña A. (2002). Learned fear, emotional reactivity and fear of heights: a factor analytic map from a large $F(2)$ intercross of Roman rat strains. Brain Research Bulletin, Vol. 57, pp. 17-26.

American Psychiatry Association. (1980). Diagnostic and Statistical Manual of Mental Disorders, $3^{\text {rd }}$ edition. American Psychiatric Press, Washington DC.

American Psychiatry Association. (1994). Diagnostic and Statistical Manual of Mental Disorders, $4^{\text {th }}$ edition. American Psychiatric Press, Washington DC. 
Bammer, G. (1983). The Australian High and Low avoidance rat strains: differential effects of ethanol and $\alpha$-methyl-p-tyrosine. Behavioural Brain Research, Vol. 8, pp. 317-333.

Battaglia, M. \& Ogliari, A. (2005). Anxiety and panic: from human studies to animal research and back. Neuroscience and Biobehavioral Reviews, Vol. 29, pp. 169-179.

Belzung, C. \& Le Pape, G. (1994). Comparison of different behavioral test situations used in psychopharmacology for measurement of anxiety. Physiology and Behavior, Vol. 56, pp. 623-628.

Bignami, G. (1965). Selection for high rates and low rates of avoidance conditioning in the rat. Animal Behaviour, Vol. 13, 221-227.

Bouton, M.E., Mineka, S. \& Barlow, D.H. (2001). A modern learning theory perspective on the etiology of panic disorder. Psychological Review, Vol. 108, pp. 4-32.

Brandão, M.L., de Aguiar, J.C. \& Graeff, F.G. (1982). GABA mediation of the anti-aversive action of minor tranquilizers. Pharmacology Biochemistry and Behavior, Vol. 16, pp. 397-402.

Brandão, M.L., Zanovelia, J.M., Ruiz-Martinez, R.C., Oliveira, L.C. \& Landeira-Fernandez, J. (2008). Different patterns of freezing behavior organized in the periaqueductal gray of rats: association with different types of anxiety. Behavioural Brain Research, Vol. 188, pp. 1-13.

Broadhurst, P.L. (1957). Determinants of emotionality in rats: I. Situational factors. British Journal of Psychology, Vol. 48, pp. 1-12.

Broadhurst, P.L. (1958). Determinant of emotionality in the rat: II. Antecedent factors. British Journal of Psychology, Vol. 49, pp. 12-20.

Broadhurst, P.L. (1975) The Maudsley reactive and non-reactive strains of rats: a survey. Behavior Genetics, Vol. 5, pp. 299-319.

Brunelli, S.A. \& Hofer, M.A. (1996). Development of ultrasonic vocalization responses in genetically heterogeneous National Institutes of Health (N:NIH) rats: II. Associations among variables and behaviors. Developmental Psychobiology, Vol. 29, pp. 517-528.

Brush, F.R., Froehlich, J.C. \& Sakellaris, P.C. (1979). Genetic selection for avoidance behavior in the rat. Behavior Genetics, Vol. 9, pp. 309-316.

Coutinho, F.C., Dias, G.P., do Nascimento Bevilaqua, M.C., Gardino, P.F., Pimentel Rangé, B. \& Nardi, A.E. (2010). Current concept of anxiety: implications from Darwin to the DSM-V for the diagnosis of generalized anxiety disorder. Expert Review of Neurotherapeutics, Vol. 10, pp. 1307-1320.

Dias, G.P., Bevilaqua, M.C., Silveira, A.C., Landeira-Fernandez, J. \& Gardino, P.F. (2009) Behavioral profile and dorsal hippocampal cells in Carioca high-conditioned freezing rats. Behavioural Brain Research, Vol. 205, pp. 342-348.

Fanselow, M.S. (1980) Conditional and unconditional components of post-shock freezing in rats. Pavlovian Journal of Biological Science, Vol. 15, pp. 177-182.

Fanselow, M.S. (1984a) What is conditioned fear? Trends in Neurosciences, Vol. 7, 460-462.

Fanselow, M.S. (1984b). Opiate modulation of the active and inactive components of the postshock reaction: parallels between naloxone pretreatment and shock intensity. Behavioral Neuroscience, Vol. 98, pp. 269-277.

Faneslow, M.S. (1990) Factors governing one trial contextual conditioning. Animal Learning and Behavior, Vol. 18, pp. 264-270. 
Fanselow, M.S. (1994) Neural organization of the defensive behavior system responsible for fear. Psychonomic Bulletin and Review, Vol. 1, pp. 429-438.

Fanselow, M.S. \& Helmstetter, F.J. (1988) Conditional analgesia, defensive freezing, and benzodiazepines. Behavioral Neuroscience, Vol. 102, pp. 233-243.

Fanselow, M.S., Helmstetter, F.J. \& Calcagnetti, D.J. (1991) Parallels between the behavioral effects of dimethoxy-carboline (DMCM) and conditional fear stimuli, In: Current Topics in Animal Learning: Brain, Emotion, and Cognition. Dachowski, L. \& Flaherty, C.F. (eds), pp. 187-206, Lawrence Erlbaum, Hillsdale.

Ferreira, T.L., Moreira, K.M., Ikeda, D.C., Bueno, O.F. \& Oliveira, M.G. (2003). Effects of dorsal striatum lesions in tone fear conditioning and contextual fear conditioning. Brain Research, Vol. 987, pp. 17-24.

File, S.E. (1992). Behavioral detection of anxiolytic action, In: Experimental Approaches to Anxiety and Depression. Elliot, J.M., Heal, D.J. \& Mardsen, C.A. (eds), pp. 25-44, John Wiley, Chichester.

Freire, R.C., Perna, G. \& Nardi, A.E. (2010). Panic disorder respiratory subtype: psychopathology, laboratory challenge tests, and response to treatment. Harvard Review of Psychiatry, Vol. 18, pp. 220-229.

Fujita, O. (1984) Tsukuba Emotionality: new selected rats. Rat News Letters Vol. 13, pp. 31.

Galvão, B.O., Gomes, V.C., Maisonnette, S. \& Landeira-Fernandez, J. (2011). Panic-like behaviors in Carioca high-and low-conditioned freezing rats. Psychology $\mathcal{E}$ Neuroscience, in press.

Gomes, V.C. \& Landeira-Fernandez, J. (2008) Amygdaloid lesions produced similar contextual fear conditioning disruption in the Carioca high- and low-conditioned freezing rats. Brain Research, Vol. 1233, pp. 137-145.

Gould, T.D. \& Gottesman, I.I. (2006). Psychiatric endophenotypes and the development of valid animal models. Genes Brain and Behavior, Vol. 5, 113-119.

Graeff, F.G. (1997). Serotonergic systems. Psychiatric Clinics of North America, Vol. 20, pp. 723739.

Graeff, F.G. \& Zangrossi, H., Jr. (2010). The dual role of serotonin in defense and the mode of action of antidepressants on generalized anxiety and panic disorders. Central Nervous System Agents in Medicinal Chemistry, Vol. 10, pp. 207-217.

Gross, C. \& Hen, R. (2004). The developmental origins of anxiety. Nature Reviews Neuroscience, Vol. 5, pp. 545-552.

Gray, J.A. (1979). Emotionality in male and female rodents: a reply to Archer. British Journal of Psychology, Vol. 70, pp. 425-440.

Gray, J.A. \& McNaughton, N. (2000). The Neuropsychology of Anxiety: An Enquiry into the Function of the Septo-Hippocampal System, 2nd edition. Oxford University Press, New York.

Grillon, C. \& Davis, M. (1997). Fear-potentiated startle conditioning in humans: explicit and contextual cue conditioning following paired versus unpaired training. Psychophysiology, Vol. 34, pp. 451-458.

Grillon, C. (2002). Startle reactivity and anxiety disorders: aversive conditioning, context, and neurobiology. Biological Psychiatry, Vol. 52, pp. 958-975.

Hall, C.S. (1934) Emotional behavior in the rat: I. Defecation and urination as measures of individual differences in emotionality. Journal of Comparative Psychology, Vol. 18, pp. 385-403. 
Hashimoto, S., Inoue, T. \& Koyama, T. (1996) Serotonin reuptake inhibitors reduce conditioned fear stress-induced freezing behavior in rats. Psychopharmacology, Vol. 123, pp. 182-186.

Indovina, I., Robbins, T.W., Núñez-Elizalde, A.O., Dunn, B.D., \& Bishop, S.J. (2011). Fearconditioning mechanisms associated with trait vulnerability to anxiety in humans. Neuron, Vol. 69, pp. 563-571.

Inoue T, Tsuchiya K, Koyama T. (1996). Effects of typical and atypical antipsychotic drugs on freezing behavior induced by conditioned fear. Pharmacology Biochemistry and Behavior, Vol 55, pp. 195-201.

Jacobson, L.H. \& Cryan, J.F. (2010). Genetic approaches to modeling anxiety in animals. Current Topics in Behavioural Neuroscience, Vol. 2, pp. 161-201.

Kahn, R.J., MacNair, D.M., Lipman, R.S., Covi, L., Rickels, K., Downing, R., Fisher, S. \& Frakenthaler, L.M. (1986). Imipramine and chlordiazepoxide in depressive and anxiety disorders: II. Efficacy in anxious outpatients. Archives of General Psychiatry, Vol. 43, pp. 79-85.

Kim, J.J. \& Fanselow, M.S. (1992). Modality-specific retrograde amnesia of fear. Science, Vol. 256, pp. 675-677.

Klein, D.F. (1964). Delineation of two drug-responsive anxiety syndromes. Psychopharmacologia, Vol. 5, pp. 397-408.

Klein, D.F. \& Fink, M. (1962). Psychiatric reaction patterns to imipramine. American Journal of Psychiatry, Vol. 119, pp. 432-438.

Landeira-Fernandez, J. (1996). Context and Pavlovian conditioning. Brazilian Journal of Medical and Biological Research, Vol. 29, pp. 149-173.

Landeira-Fernandez, J., DeCola, J.P., Kim, J.J. \& Fanselow, M.S. (2006). Immediate shock deficit in fear conditioning: effects of shock manipulations. Behavioral Neuroscience, Vol. 120, pp. 873-879.

Landeira-Fernandez, J., Fanselow, M.S., DeCola, J.P. \& Kim, J.J. (1995). Effects of handling and context preexposure on the immediate shock deficit. Animal Learning and Behaviour, Vol. 23, pp. 335-339.

LeDoux, J.E. (2000). Emotion circuits in the brain. Annual Review of Neuroscience, Vol. 23, pp. 155-184.

Liebsch, G., Linthorst, A.C., Neumann, I.D., Reul, J.M., Holsboer, F. \& Landgraf, R. (1998a). Behavioral, physiological, and neuroendocrine stress responses and differential sensitivity to diazepam in two Wistar rat lines selectively bred for highand lowanxiety-related behavior. Neuropsychopharmacology, Vol. 19, pp. 381-396.

Liebsch, G., Montkowski, A., Holsboer, F. \& Landgraf, R. (1998b). Behavioural profiles of two Wistar rat lines selectively bred for high or low anxiety-related behavior. Behavioural Brain Research, Vol. 94, pp. 301-310.

Maki, Y., Inoue, T., Izumi, T., Muraki, I., Ito, K., Kitaichi, Y., Li, X. \& Koyama, T. (2000). Monoamine oxidase inhibitors reduce conditioned fear stress-induced freezing behavior in rats. European Journal of Pharmacology, Vol. 406, pp. 411-418.

Marks, I.M., \& Nesse, R.M. (1994). Fear and fitness: an evolutionary analysis of anxiety disorders. Ethology and Sociobiology, Vol. 15, pp. 247-261.

Ohta, R., Matsumoto, A., Hashimoto, Y., Nagao, T. \& Mizutani, M. (1995). Behavioral characteristics of rats selectively bred for high and low avoidance shuttlebox response. Cong Anom Vol. 35, pp. 223-229. 
Oliveira, L.C., Nobre, M.J., Brandão, M.L. \& Landeira-Fernandez, J. (2004). Role of amygdala in conditioned and unconditioned fear generated in the periaqueductal gray. Neuroreport, Vol. 15, pp. 2281-2285.

Pavlov, I. (1927). Conditioned Reflexes: An Investigation of the Physiological Activity of the Cerebral Cortex. Oxford University Press, London.

Pohlack, S.T., Nees, F., Liebscher, C., Cacciaglia, R., Diener, S.J., Ridder, S., Woermann, F.G. \& Flor, H. (2011). Hippocampal but not amygdalar volume affects contextual fear conditioning in humans. Human Brain Mapping, in press.

Ramos, A., Berton, O., Mormède, P. \& Chaouloff, F. (1997) A multiple-test study of anxietyrelated behaviors in six inbred rat strains. Behavioural Brain Research, Vol. 85, pp. 5769.

Ramos, A., Correia, E.C., Izídio, G.S. \& Brüske, G.R. (2003). Genetic selection of two new rat lines displaying different levels of anxiety-related behaviors. Behavior Genetics, Vol. 33, pp. 657-668.

Ramos, A. \& Mormède, P. (2006) Genetic analisis of emotional behaviors using animal models, In: Neurobehavioral Genetics: Methods and Applications. Jones, B.C. \& Mormède, P. (eds), pp. 291-303, Taylor and Francis, London.

Ryzhova, L.Y., Kulagin, D.A. \& Lopatina, N.G. (1983) Correlated variability in motor activity and emotionality in selecting rats for high and low values of active avoidance conditioned reflexes. Genetika, Vol. 19, pp. 121-125.

Schweizer, E., Rickels, K., Weiss, S. \& Zavodnick, S. (1993). Maintenance drug treatment for panic disorder: I. Results of a prospective, placebo-controlled comparizon of alprazolam and imipramine. Archives of General Psychiatry, Vol. 50, pp. 51-60.

Sigmundi, R.A., Bouton, M.E. \& Bolles, R.C. (1980) Conditioned freezing in the rat as a function of shock intensity and CS modality. Bulletin of the Psychonomic Society, Vol. 15, pp. 254-256.

Stein, M., Steckler, T., Lightfoot, J.D., Hay, E. \& Goddard, A.W. (2010). Pharmacologic treatment of panic disorder. Current Topics in Behavioral Neurosciences, Vol. 2, pp. 469-485.

Torrejais, J.C., Rosa, C.C., Boerngen-Lacerda, R. \& Andreatini, R. (2008) The elevated T-maze as a measure of two types of defensive reactions: a factor analysis. Brain Research Bulletin, Vol. 76, pp. 376-379.

Vianna, D.M., Graeff, F.G., Brandão, M.L. \& Landeira-Fernandez, J. (2001a) Defensive freezing evoked by electrical stimulation of the periaqueductal gray: comparison between dorsolateral and ventrolateral regions. Neuroreport, Vol. 12, pp. 4109-4112.

Vianna, D.M., Landeira-Fernandez, J, \& Brandão, M.L. (2001b). Dorsolateral and ventral regions of the periaqueductal gray matter are involved in distinct types of fear. Neuroscience and Biobehavioral Reviews, Vol. 25, pp. 711-779.

World Health Organization (1992). International Statistical Classification of Diseases and Related Health Problems. World Health Organization, Geneva.

Watson, J.B. \& Rayner, R. (1920). Conditioned emotional reactions. Journal of Experimental Psychology, Vol. 3, pp. 1-14. 


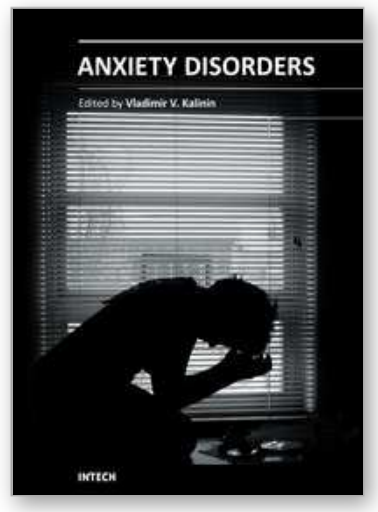

\author{
Anxiety Disorders \\ Edited by Prof. Vladimir Kalinin
}

ISBN 978-953-307-592-1

Hard cover, 324 pages

Publisher InTech

Published online 01, August, 2011

Published in print edition August, 2011

During the last 2-3 decades drastic research progress in anxiety issues has been achieved. It concerns mostly the study of different subtypes of anxiety and their treatment. Nevertheless, the data on anxiety pathogenesis is less elaborated, although here a multidimensional approach exists. It includes neurochemistry, pathophysiology, endocrinology and psychopharmacology. Again, we are able to recognize the multifarious sense of anxiety, and the present collective monograph composed of 16 separate chapters depicting the different aspects of anxiety. Moreover, a great part of book includes chapters on neurochemistry, physiology and pharmacology of anxiety. The novel data on psychopathology and clinical signs of anxiety and its relationship with other psychopathological phenomena is also presented. The current monograph may represent an interest and be of practical use not only for clinicians but for a broad range of specialists, including biochemists, physiologists, pharmacologists and specialists in veterinary.

\title{
How to reference
}

In order to correctly reference this scholarly work, feel free to copy and paste the following:

Vitor de Castro Gomes, Carlos Eduardo Barroso Silva and J. Landeira-Fernandez (2011). The Carioca High and Low Conditioned Freezing Lines: A New Animal Model of Generalized Anxiety Disorder, Anxiety Disorders, Prof. Vladimir Kalinin (Ed.), ISBN: 978-953-307-592-1, InTech, Available from:

$\mathrm{http}: / / \mathrm{www}$.intechopen.com/books/anxiety-disorders/the-carioca-high-and-low-conditioned-freezing-lines-anew-animal-model-of-generalized-anxiety-disor 1

\section{INTECH}

open science | open minds

\section{InTech Europe}

University Campus STeP Ri

Slavka Krautzeka 83/A

51000 Rijeka, Croatia

Phone: +385 (51) 770447

Fax: +385 (51) 686166

www.intechopen.com

\section{InTech China}

Unit 405, Office Block, Hotel Equatorial Shanghai

No.65, Yan An Road (West), Shanghai, 200040, China

中国上海市延安西路65号上海国际贵都大饭店办公楼 405 单元

Phone: +86-21-62489820

Fax: $+86-21-62489821$ 
(C) 2011 The Author(s). Licensee IntechOpen. This chapter is distributed under the terms of the Creative Commons Attribution-NonCommercialShareAlike-3.0 License, which permits use, distribution and reproduction for non-commercial purposes, provided the original is properly cited and derivative works building on this content are distributed under the same license. 